\title{
Multiplex-RT-PCR-ELISA panel for detecting mosquito-borne pathogens: Plasmodium sp. preserved and eluted from dried blood spots on sample cards
}

\author{
Philip Koliopoulos ${ }^{1}$, Neema Mathias Kayange ${ }^{2}$, Tim Daniel ${ }^{1}$, Florian Huth ${ }^{6}$, Britta Gröndahl ${ }^{1^{*}(1)}$ \\ , Grey Carolina Medina-Montaño ${ }^{1}$, Leah Pretsch ${ }^{1}$, Julia Klüber ${ }^{1,7}$, Christian Schmidt $^{4}$, Antke Züchner ${ }^{2}$, \\ Sebastian Ulbert ${ }^{5}$, Steven E. Mshana ${ }^{3}$, Marylyn Addo ${ }^{6}$ and Stephan Gehring ${ }^{1}$
}

\begin{abstract}
Background: Children are the most vulnerable group affected by malaria and other tropical, vector-borne diseases in low-resource countries. Infants presenting with acute onset fever represent a major sector of outpatient care in the Lake Victoria region. Misclassification and overuse of antibiotics and anti-malarial medications are consistent problems. Identifying the prevalent mosquito-borne pathogens in the region will reduce the prescription of non-indicated medicines.

Methods: The literature was reviewed focusing on the mosquito-borne pathogens most prevalent in sub-Saharan Africa. Accordingly, an assay comprised of a multiplex-reverse transcriptase-polymerase chain reaction and an enzyme-linked immunosorbent assay (multiplex-RT-PCR-ELISA) was designed and validated in its ability to identify and differentiate nine human mosquito-borne pathogens including eight arboviruses and Plasmodium sp., the aetiologic agents of malaria. Blood samples obtained from 132 children suspected of having malaria were spotted and preserved on Whatman ${ }^{\circledR} 903$ protein sample cards. Multiplex-RT-PCR-ELISA analysis was assessed and compared to results obtained by blood smear microscopy and the malaria rapid diagnostic test (RDT).

Results: Nine out of nine pathogens were amplified specifically by the multiplex-RT-PCR-ELISA panel. Twenty-seven out of 132 paediatric patients presenting with acute fever were infected with Plasmodium sp., confirmed by multiplexRT-PCR. The results of blood smear microscopy were only $40 \%$ sensitive and $92.8 \%$ specific. The malaria RDT, on the other hand, detected acute Plasmodium infections with $96.3 \%$ sensitivity and $98.1 \%$ specificity. The preservation of Plasmodium sp. in clinical sera and whole blood samples spotted on sample cards was evaluated. The duration of successful, sample card storage was 186 to 312 days.
\end{abstract}

Conclusions: Reliable, easy-to-use point of care diagnostic tests are a powerful alternative to laboratory-dependent gold standard tests. The multiplex-RT-PCR-ELISA amplified and identified nine vector-borne pathogens including Plasmodium sp. with great accuracy. Translation of improved diagnostic approaches, i.e., multiplex-RT-PCR-ELISA, into effective treatment options promises to reduce childhood mortality and non-indicated prescriptions.

\footnotetext{
*Correspondence: groendahl@uni-mainz.de

${ }^{1}$ Center of Pediatric and Adolescent Medicine, University Medical Center, Mainz, Germany
}

Full list of author information is available at the end of the article

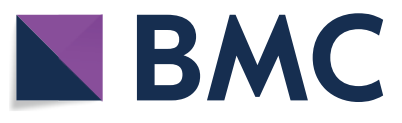

(c) The Author(s) 2021. This article is licensed under a Creative Commons Attribution 4.0 International License, which permits use, sharing, adaptation, distribution and reproduction in any medium or format, as long as you give appropriate credit to the original author(s) and the source, provide a link to the Creative Commons licence, and indicate if changes were made. The images or other third party material in this article are included in the article's Creative Commons licence, unless indicated otherwise in a credit line to the material. If material is not included in the article's Creative Commons licence and your intended use is not permitted by statutory regulation or exceeds the permitted use, you will need to obtain permission directly from the copyright holder. To view a copy of this licence, visit http://creativeco mmons.org/licenses/by/4.0/. The Creative Commons Public Domain Dedication waiver (http://creativecommons.org/publicdomain/ zero/1.0/) applies to the data made available in this article, unless otherwise stated in a credit line to the data. 
Keywords: Acute febrile diseases, Plasmodium falciparum, Sub-Saharan-Africa, Malaria rapid diagnostic test, Whatman filter cards, Dried blood spots, Mosquito-borne diseases, Dengue virus, Multiplex-RT-PCR-ELISA, Tanzania

\section{Background}

Acute mosquito-transmitted febrile diseases are a serious threat to children in sub-Saharan Africa (SSA). According to the World Health Organization (WHO) World Malaria Report 2018, 266,000 children in Africa died from malaria making up for $61 \%$ off all malaria deaths worldwide [1].

Increased focus on Plasmodium sp., the aetiologic agents of malaria, has led to a significant decline in the incidence of disease in Tanzania due mainly to prophylactic measures [2]. Four out of five cases of malaria identified by microscopic evaluation of blood smears in rural areas of Southern Tanzania are false positives [3]. "Negative syndrome" applies to children with malaria-like symptoms, but unconfirmed malaria. The malaria rapid diagnostic test (RDT) is a reliable, easy to use method that detects antigens specific to Plasmodium sp. Negative test results led to a decrease in the prescription of nonindicated, artemisinin-based anti-malarial drugs in lowresource settings [4].

Regrettably, an increasing number of malaria-like diseases caused by viral and bacterial pathogens have gained importance in recent years. Certain arboviruses, like Dengue (DENV) and Chikungunya (CHIKV) viruses, are responsible for huge epidemic outbreaks worldwide [5]. Since DENV is endemic in more than 125 countries, over $50 \%$ of the world's population is at risk of infection [6]. The presence of DENV and CHIKV throughout sub-Saharan Africa (SSA) is likely and outbreak events are reported regularly, but reliable epidemiologic data are currently lacking $[7,8]$. Inadequate treatment decisions are unavoidable due to the lack of diagnostic tools capable of distinguishing between pathogens [9]. Consequently, significant health, financial, and logistic burdens are inevitable for SSA communities [10]. Epidemiologic and diagnostic recognition of the relevant, circulating pathogens is indispensable for paediatric health care in the Lake Victoria Region, Tanzania. Moreover, it could inform the future aspects of arboviral spread to other continents [11-13].

A combination of a conventional multiplex-reverse transcriptase-polymerase chain reaction and an enzymelinked immunosorbent assay (multiplex-RT-PCR-ELISA) in a microwell plate is a well-established, low-cost method used to detect multiple pathogens simultaneously [14]. The ability of multiplex-RT-PCR-ELISA to detect multiple pathogens in a single sample makes it highly valuable for distinguishing between different pathogens that cause acute febrile diseases. Unfortunately, current multiplex-RT-PCR methods focusing on arboviruses usually include DENV and CHIKV, but often omit other important pathogens, such as Zika virus (ZIKV), Rift Valley fever virus (RVFV) and Yellow fever virus (YFV) $[15,16]$.

Dried blood spots (DBS) on sample cards are a common approach used to preserve viral nucleic acids for subsequent diagnosis. DBS sample cards proved to be of tremendous value in epidemiologic studies that evaluated the prevalence of HIV, HCV, and HBV [17] and DENV [18], CHIKV [19] and Plasmodium sp. [20]. Notably, the WHO provided an algorithm in 2010 to detect treatment-resistant HIV strains by DBS-based RT-PCR [21]. Importantly, the WHO advises screening for "neglected tropical diseases" using developing technologies applicable to the most affected countries [22]. The preservation capacity of sample cards containing serum samples obtained from patients with arbovirus infections show concordance rates up to $95 \%$ [23].

The study described herein was undertaken to design a diagnostic test to identify, and distinguish between, the vector-borne pathogens capable of causing acute fever in children in SSA. A principal focus was optimizing the collection and storage of blood samples obtained from children in low resource settings like SSA. To this end, an established protocol for preparing and processing HIV-, HBV- and HCV-positive DBS samples was modified to accommodate the conditions found in SSA.

\section{Methods}

\section{Patient population}

A hospital-based cross-sectional prospective study was initiated at Bugando Medical Centre in Mwanza, Tanzania. Sociodemographic clinical data and blood samples were collected consecutively between April 2016 and October 2016 from 132 children, 5-months to 12-years of age. The children presented with acute high-grade fever $\left(>38.0^{\circ} \mathrm{C}\right)$ and met the criteria of a presumptive malaria infection according to WHO definitions [24].

\section{Sample collection and storage}

Venous blood $(400 \mu \mathrm{l})$ was collected from each patient, centrifuged and stored at $-20{ }^{\circ} \mathrm{C}$. The NADAL ${ }^{\circledR}$ Malaria $\mathrm{Pf} / \mathrm{Pan} \mathrm{Ag} 4$ Species Test (nal von minden $\mathrm{GmbH}$, Regensburg, Germany) was performed and the results of blood smear microscopy for malaria were obtained at the respective health facility. Whatman ${ }^{\circledR} 903$ protein sample cards, spotted with patient whole blood or sera at the 
time of collection, were dried and prepared according to a modification of the protocol of Grüner described below [17]. Sample cards were stored at room temperature under dry conditions for 6- to 10-months in zip-locked plastic bags containing desiccant sachets. The frozen sera and spotted card samples were shipped to University of Mainz, Department of Pediatric Immunology and Infectious Diseases according to IATA and ICAO regulations.

\section{Sample card extraction}

Whole blood and serum spotted on sample cards were processed by a modification of the methods reported in a study by Grüner et al, which validated this approach in a comparison of 1,762 paired, serum and DBS samples [17]. DBS elution is the crucial step to generating intact nucleic acid and serologic markers for testing. DBS elution was optimized by spotting $50 \mu \mathrm{l}$ whole blood obtained from Plasmodium falciparum and Plasmodium vivax patients on Whatman ${ }^{\circledR} 903$ protein sample cards. The cards were dried for $24 \mathrm{~h}$ and stored in zip-locked plastic bags for two weeks under dry condition at room temperature according to Grüner et al. [17]. The card punch procedure was standardized with a $3 \mathrm{~mm}$ wide hole. Six holes were punched from each sample blood spot, two from the centre and four from outer edge of the field; the six sample disks were transferred directly to a reaction tube. To prevent carryover and false positive results, card punches were rinsed sequentially for $30 \mathrm{~s}$ in the following solutions: distilled water; DNA-ExitusPlus ${ }^{\text {TM }}$ (decontamination reagent, AppliChem GmbH, Darmstadt, Germany); distilled water and Terralin ${ }^{\circledR}$ liquid (alcohol-based disinfectant, Schülke \& Mayr GmbH, Norderstedt, Germany). The card punch was air-dried afterwards.

The capacity of DBS to preserve pathogen-derived nucleic acid was validated by spotting positive controls on sample cards and testing three different elution methods (Fig. 1; Table 1). Incubation and shaking at high temperatures were performed in a heating block (Eppendorf ${ }^{\circledR}$ Thermomixer ${ }^{\circledR}$ ); overnight incubation at room temperature was performed in a three-dimensional shaker (TL10 Edmund Bühler). After elution, the sample was centrifuged for $3 \mathrm{~min}$ at $8000 \mathrm{rpm}$ and the aqueous phase was transferred to a new reaction tube. The supernatant was stored at $-20{ }^{\circ} \mathrm{C}$ and multiplex-RT-PCR-ELISA was performed as outlined below within 2 months following extraction.

\section{Primers, probes and positive controls}

Primer sets and biotinylated capture probes, selected based upon recent publications devoted to mosquitotransmitted pathogens in SSA (cited in Table 2), were purchased from ThermoFisher Invitrogen Custom DNA Oligonucleotides (Darmstadt, Germany). The influenza A primer set (primer 1, 5'-AAGGGCTTTCAC CGAAGAGG-3'; primer 2, 5'-CCCATTCTCATTACT GCTTC- $3^{\prime}$ ) and capture probe (5'-GTCAAGAGCACC GATTATCAC-3'), which were not components of the

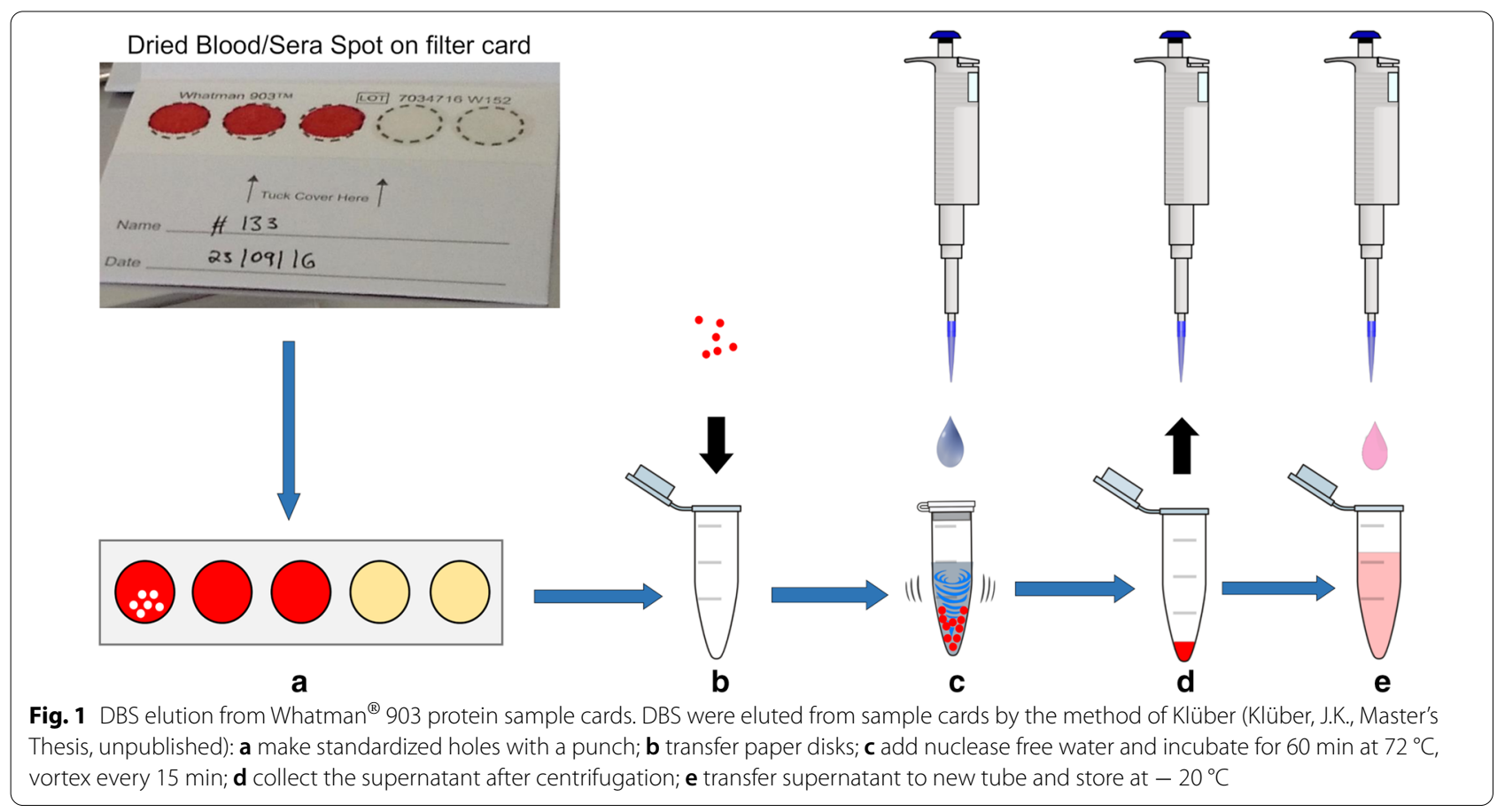


Table 1 Sample card extraction

\begin{tabular}{|c|c|c|c|}
\hline & Klüber method ${ }^{a}$ & Klüber-Grüner method & Grüner method [17] \\
\hline Amount & Six paper disks (3 mm) & Six paper disks (3 mm) & Six paper disks (3 mm) \\
\hline Time & $1 \mathrm{~h}$ at $750 \mathrm{rpm}$ & $1 \mathrm{~h}$ at $750 \mathrm{rpm}$ & Gently shaking overnight \\
\hline Temperature & $72^{\circ} \mathrm{C}$ & $72^{\circ} \mathrm{C}$ & Room temperature \\
\hline Buffer/process & $\begin{array}{l}300 \mu \text { l of nuclease-free water. Vortex } \\
\text { reaction tubes every } 15 \text { min }\end{array}$ & $\begin{array}{l}300 \mu \mathrm{l} \text { PBS-buffer containing Tween } 20 \text { and 0.9\% } \\
\mathrm{NaCl} \text {. Vortex reaction tubes every } 15 \mathrm{~min}\end{array}$ & $\begin{array}{l}300 \mu \text { l of PBS-buffer } \\
\text { containing Tween } 20 \text { and } \\
0.9 \% \mathrm{NaCl}\end{array}$ \\
\hline
\end{tabular}

Positive controls spotted on Whatman ${ }^{\circledR} 903$ protein sample cards were extracted by one of the three methods indicated

a J. Klüber, Master's Thesis, unpublished

multiplex-RT-PCR-ELISA, were also purchased from ThermoFisher. The positive control for influenza A (inactivated virus particles) was obtained from Laboratory of Pediatric Immunology and Infectious Diseases, Mainz, Germany. Positive controls for all other organisms were obtained from the institutions listed Table 3. A singleplex-PCR validated the usefulness of the selected primers. The primers were subsequently incorporated into the multiplex-RT-PCR-ELISA panel for malaria-like diseases. To cover a broad range of mosquito transmittable diseases without overloading the multiplex-RT-PCR master mix, primer pairs covering DENV $1-4$ and the clinical relevant Plasmodium sp. were included into the multiplex-RT-PCR-panel $[25,26]$ (Table 3). Remarkably, the Plasmo Plu3 primerset targets genus-specific the plasmodium $18 \mathrm{~S}$ rRNA Gene and thereby grants enhanced sensitivity through the RT-step.

Plasmodium sp. (P. falciparum, Plasmodium ovale, Plasmodium malariae) were differentiated in a trivalentRT-PCR. Positive controls, whole blood obtained from patients infected with Plasmodium sp. listed (Discovery Life Science, Inc., Los Osos, TX, USA), were tested. DENV serotyping using inactivated DENV 1-4 was performed subsequent to multiplex-RT-PCR to delineate the epidemiology of DENV infections in SSA.

\section{Multiplex-RT-PCR-ELISA}

Total nucleic acid was isolated with the High Pure Viral Nucleic Acid Kit according to the manufacturer's instructions (Roche Diagnostics, Mannheim, Germany). Purified nucleic acid $(4.5 \mu \mathrm{l})$ was used as the template for multiplex-RT-PCR-ELISA in accordance with methods described previously [14, 27, 28]. Target sequences for PCR were selected from the literature (Table 2).

The PCR product was denatured with $\mathrm{NaOH}$ and quantified by adding $15 \mu \mathrm{l} /$ well to streptavidin-coated microtitre plates. The 3 'biotinylated capture probe specific for the amplified target sequence (also listed in Table 2) was then added and the plates were incubated for at least $1.5 \mathrm{~h}$ at $37{ }^{\circ} \mathrm{C}$. After washing, anti-digoxigenin-peroxidase (Roche Diagnostics) was added and the plates were reincubated for $45 \mathrm{~min}$ and washed. ABTS substrate solution (Roche Diagnostics) was added to each well, and the plates were incubated for another $30 \mathrm{~min}$ at $37^{\circ} \mathrm{C}$. The optical density $\left(\mathrm{OD}_{405}\right)$, $492 \mathrm{~nm}$ reference filter, was determined. Positive and negative controls were included in each assay. The results were considered valid if all negative control values were $\leq 0.2 \mathrm{OD}_{405}$. Samples were classified as PCR-positive or -negative dependent upon a $0.4 \mathrm{OD}_{405}$ cut-off value; samples with initial values of $0.2-0.4$ $\mathrm{OD}_{405}$ were considered borderline and only classified as positive or negative after retesting with a singleplex PCR approach.

The sensitivity of the multiplex-RT-PCR-ELISA panel was determined using ZIKV strain MR766 $\left(1 \times 10^{7}\right.$ viral RNA copies/ml) obtained from the Robert Koch Institute as a positive control. Viral RNA was mixed with nuclease free $\mathrm{H}_{2} \mathrm{O}$ and serially diluted 10 -fold to establish the minimal detectable viral copies. Multiplex-RTPCR-ELISA was performed on serial dilutions of the ZIKV standard in a master mix containing the 9 primer pairs described above. Specificity was evaluated by quantifying the OD-values of the nine-fold hybridized PCR product.

Multiplex-RT-PCR-ELISA was performed on all frozen sera and samples derived from DBS and DSS. All samples, which were positive for mosquito-borne disease, were retested by multiplex-RT-PCR-ELISA and verified by a singleplex PCR approach (Plasmo Plu3 primerset, Table 2) using the primer set found to be the most sensitive among seven published sets targeting Plasmodium sp. or P. falciparum [29]. The patients' clinical information, RDT and blood smear test results were known to the assessor of Multiplex-RT-PCRELISA performed on patients' filtercards and sera samples. Contrariwise Multiplex-RT-PCR-ELISA test results of patients' samples were not known to the performer of mRDT or blood smear tests. 
Table 2 Multiplex-RT-PCR-ELISA: primers and probes

\begin{tabular}{|c|c|c|c|c|c|c|c|}
\hline & Family & No & $\begin{array}{l}\text { Pathogens } \\
\text { and prevalence }\end{array}$ & Primer & $5^{\prime}-3^{\prime}$ sequence & $\begin{array}{l}\text { Concentration } \\
(\mathrm{pm} / \mu \mathrm{l})\end{array}$ & Literature $^{a}$ \\
\hline \multirow[t]{28}{*}{ Arboviruses } & \multirow[t]{16}{*}{ Flaviviridae } & \multirow[t]{6}{*}{1} & \multirow[t]{2}{*}{$\begin{array}{l}\text { Dengue virus (DENV) }[8, \\
42,61,62]\end{array}$} & C-prm D1 & $\begin{array}{l}\text { TCAATATGCTGAAACGCG } \\
\text { AGAGAAACCG }\end{array}$ & 5.5 & \multirow[t]{6}{*}[25]{$^{\mathrm{b}, \mathrm{c}}$} \\
\hline & & & & D2 & $\begin{array}{l}\text { TTGCACCAACAGTCAATG } \\
\text { TCTTCAGGTTC }\end{array}$ & 5.5 & \\
\hline & & & DENV-1 ${ }^{d}$ & rTS1 (DEN-1) & $\begin{array}{l}\text { CCCGTAACACTTTGATCG } \\
\text { CT }\end{array}$ & 5.5 & \\
\hline & & & DENV- ${ }^{d}$ & mTS2 (DEN-2) & $\begin{array}{l}\text { CGCCACAAGGGCCATGAA } \\
\text { CAGTTT }\end{array}$ & 5.5 & \\
\hline & & & DENV- $3^{d}$ & TS3 (DEN-3) & $\begin{array}{l}\text { TAACATCATCATGAGACA } \\
\text { GAGC }\end{array}$ & 5.5 & \\
\hline & & & DENV-4 ${ }^{d}$ & rTS4 (DEN-4) & $\begin{array}{l}\text { TTCTCCCGTTCAGGATGT } \\
\text { TC }\end{array}$ & 5.5 & \\
\hline & & \multirow[t]{3}{*}{2} & \multirow{3}{*}{$\begin{array}{l}\text { West Nile virus (WNV) } \\
\text { [63-65] }\end{array}$} & WNV lancio F & CAGACCACGCTACGGCG & 5.5 & \multirow[t]{3}{*}[66]{$^{b}$} \\
\hline & & & & WNV lancio R & CTAGGGCCGCGTGGG & 5.5 & \\
\hline & & & & WNV lancio P & $\begin{array}{l}\text { TCTGCGGAGAGTGCAGTC } \\
\text { TGCGAT }\end{array}$ & 10 & \\
\hline & & \multirow[t]{4}{*}{3} & \multirow[t]{4}{*}{ Zika virus (ZIKV) [67, 68] } & ZVforw & $\begin{array}{l}\text { CAGCTGGCATCATGAAGA } \\
\text { AYC }\end{array}$ & 5.5 & \multirow[t]{4}{*}[70]{$^{\mathrm{b}}$} \\
\hline & & & & ZVrev1 & $\begin{array}{l}\text { CACTTGTCCCATCTTCTT } \\
\text { CTCC }\end{array}$ & 5.5 & \\
\hline & & & & ZVrev2 & $\begin{array}{l}\text { CACCTGTCCCATCTTTTT } \\
\text { CTCC }\end{array}$ & 5.5 & \\
\hline & & & & ZVprobe & $\begin{array}{l}\text { CYGTTGTGGATGGAATAG } \\
\text { TGG }\end{array}$ & 10 & \\
\hline & & \multirow[t]{3}{*}{4} & \multirow[t]{3}{*}{$\begin{array}{l}\text { Yellow Fever virus (YFV) } \\
\text { [69-71] }\end{array}$} & YFV-F & $\begin{array}{l}\text { GCACGGATGTAACAGACT } \\
\text { GAAGA }\end{array}$ & 5.5 & \multirow[t]{3}{*}[72]{$^{b}$} \\
\hline & & & & YFV-R & CCAGGCCGAACCTGTCAT & 5.5 & \\
\hline & & & & YFV-probe & $\begin{array}{l}\text { CGACTGTGTGGTCCGGCC } \\
\text { CTC }\end{array}$ & 10 & \\
\hline & \multirow[t]{9}{*}{$\begin{array}{l}\text { Togaviridae (Alphaviruses) } \\
\text { [37] }\end{array}$} & \multirow[t]{3}{*}{5} & \multirow[t]{3}{*}{$\begin{array}{l}\text { Semliki Forest virus (SFV) } \\
\text { [64] }\end{array}$} & SFV-F & $\begin{array}{l}\text { ACAGACTGTCACTGA } \\
\text { GCAG }\end{array}$ & 5.5 & \multirow[t]{3}{*}[75]{$^{\mathrm{b}}$} \\
\hline & & & & SFV-R & $\begin{array}{l}\text { AGCTCCACGTCATCATTG } \\
\text { AG }\end{array}$ & 5.5 & \\
\hline & & & & SFV-probe & $\begin{array}{l}\text { GTGACCATCTACTGCAGA } \\
\text { GA }\end{array}$ & 10 & \\
\hline & & \multirow[t]{3}{*}{6} & \multirow[t]{3}{*}{$\begin{array}{l}\text { O'nyong-nyong virus } \\
\text { (ONNV) [74-76] }\end{array}$} & ONNV-F & $\begin{array}{l}\text { GCAGGGAGGCCAGGA } \\
\text { CAGT }\end{array}$ & 5.5 & \multirow[t]{3}{*}[79]{$^{b}$} \\
\hline & & & & ONNV-R & $\begin{array}{l}\text { GCCCCTTTTTCYTTGAGC } \\
\text { CAGTA }\end{array}$ & 5.5 & \\
\hline & & & & ONNV-probe & $\begin{array}{l}\text { TGTATTGCTCCTGCCGCT } \\
\text { GG }\end{array}$ & 10 & \\
\hline & & \multirow[t]{3}{*}{7} & \multirow[t]{3}{*}{$\begin{array}{l}\text { Chikungunya virus (CHIKV) } \\
{[42,76,78,79]}\end{array}$} & Chiks & $\begin{array}{l}\text { TGATCCCGACTCAACCAT } \\
\text { CCT }\end{array}$ & 5.5 & \multirow[t]{3}{*}[82]{$^{\mathrm{b}}$} \\
\hline & & & & ChikAs & $\begin{array}{l}\text { GGCAAACGCAGTGGTACT } \\
\text { TCCT }\end{array}$ & 5.5 & \\
\hline & & & & ChikP & $\begin{array}{l}\text { TCCGACATCATCCTCCTT } \\
\text { GCTGGC }\end{array}$ & 10 & \\
\hline & \multirow[t]{3}{*}{ Bunyaviridae } & \multirow[t]{3}{*}{8} & \multirow[t]{3}{*}{$\begin{array}{l}\text { Rift Valley fever virus } \\
\text { (RVFV) }[81,82]\end{array}$} & RVF-F & $\begin{array}{l}\text { TGAAAATTCCTGAGACAC } \\
\text { ATGG }\end{array}$ & 5.5 & \multirow[t]{3}{*}[79]{$^{b}$} \\
\hline & & & & RVF-R & $\begin{array}{l}\text { ACTTCCTTGCATCATCTG } \\
\text { ATG }\end{array}$ & 5.5 & \\
\hline & & & & RVF-probe & $\begin{array}{l}\text { CACAAGTCCACACAGGCC } \\
\text { CCTTACAT }\end{array}$ & 10 & \\
\hline
\end{tabular}


Table 2 (continued)

\begin{tabular}{|c|c|c|c|c|c|c|c|}
\hline & Family & No & $\begin{array}{l}\text { Pathogens } \\
\text { and prevalence }\end{array}$ & Primer & $5^{\prime}-3^{\prime}$ sequence & $\begin{array}{l}\text { Concentration } \\
(\mathrm{pm} / \mu \mathrm{l})\end{array}$ & Literature $^{a}$ \\
\hline \multirow[t]{12}{*}{ Protozoa } & \multirow[t]{12}{*}{ Malaria (Plasmodium sp.) } & \multirow[t]{12}{*}{9} & \multirow[t]{3}{*}{ Plasmodium sp. (MAL) [83] } & Plasmo Plu3 F & $\begin{array}{l}\text { GCTCTTTCTTGATTTCTT } \\
\text { GGATG }\end{array}$ & 5.5 & \multirow[t]{3}{*}[26]{$^{b}$} \\
\hline & & & & Plasmo Plu3 R & $\begin{array}{l}\text { AGCAGGTTAAGATCTCGT } \\
\text { TCG }\end{array}$ & 5.5 & \\
\hline & & & & Plasmo Plu3 P & $\begin{array}{l}\text { ATGGCCGTTTTTAGTTCG } \\
\text { TG }\end{array}$ & 10 & \\
\hline & & & \multirow[t]{3}{*}{ P. falciparum [84] } & FAL-F & $\begin{array}{l}\text { CTTTTGAGAGGTTTTGTT } \\
\text { ACTTTGAGTAA }\end{array}$ & 5.5 & \multirow[t]{3}{*}[51]{$^{e}$} \\
\hline & & & & FAL-R & $\begin{array}{l}\text { TATTCCATGCTGTAGTAT } \\
\text { TCAAACACAA }\end{array}$ & 5.5 & \\
\hline & & & & FAL-probe & $\begin{array}{r}\text { TGTTCATAACAGACGGGT } \\
\text { AGTCATGATTGAGTTCA }\end{array}$ & 10 & \\
\hline & & & \multirow[t]{3}{*}{ P. vivax [85] } & VIV-F & $\begin{array}{l}\text { ACGCTTCTAGCTTAATCC } \\
\text { ACATAACT }\end{array}$ & 5.5 & \multirow[t]{3}{*}[88]{$^{e}$} \\
\hline & & & & VIV-R & $\begin{array}{l}\text { ATTTACTCAAAGTAACAA } \\
\text { GGACTTCCAAGC }\end{array}$ & 5.5 & \\
\hline & & & & VIVAX-probe & $\begin{array}{l}\text { TTCGTATCGACTTTGTGC } \\
\text { GCATTTTGC }\end{array}$ & 10 & \\
\hline & & & \multirow[t]{3}{*}{ P. malariae $[87,88]$} & Pm-1 & $\begin{array}{l}\text { AGTTAAGGGAGTGAAGAC } \\
\text { GATCAGA }\end{array}$ & 5.5 & \multirow[t]{3}{*}[89]{$^{e}$} \\
\hline & & & & Pm-2 & $\begin{array}{l}\text { CAACCCAAAGACTTTGAT } \\
\text { TTCTCATAA }\end{array}$ & 5.5 & \\
\hline & & & & Pm-probe & $\begin{array}{l}\text { ATGAGTGTTTCTTTTAGA } \\
\text { TAGC }\end{array}$ & 10 & \\
\hline
\end{tabular}

a The primers and probes listed were obtained from the literature cited

b Included in the multiplex-RT-PCR-ELISA

c Used to type DENV1-4 according to the method of Chien et al. [25]

d Probes for DENV1-4 consisted of the respective biotinylated primers

e Used to differentiate Plasmodium sp. by multiplex-RT-PCR-ELISA

\section{Biosafety}

The isolation and extraction of pathogen nucleic acid were conducted following strict biosecurity standards in a biosafety level 2 cabinet. Each series of 9 specimens included one negative control $(\mathrm{NaCl})$ to monitor crosscontamination. Nucleic acid extractions and the preparation of PCR-reagents were carried out in different rooms. Terralin ${ }^{\circledR}$ liquid and UV light $(30 \mathrm{~min})$ were used at the end of each step to negate contamination [30].

\section{Statistical analysis}

The sensitivity and specificity of two standard diagnostic tests for malaria (i.e., blood smear microscopy and the RDT) were evaluated using two-by-two tables comparing the results of each test with those obtained by multiplex-RT-PCR-ELISA on serum samples derived from the same patient. An interrater reliability analysis was conducted using the Cohen's kappa statistic to determine consistency among the preservation methods, i.e.,
DBS versus DSS. The results were classified according to Byrd et al: $\mathrm{\kappa}=0.93-1.0$, excellent; $\mathrm{\kappa}=0.81-0.92$, very good; $\kappa=0.61-0.80$, good; $\kappa=0.41-0.60$, satisfactory; $\kappa=0.21-0.40$, slight; $\kappa=0.01-0.20$, weak; and $\kappa \leq 0$, no agreement [31]. The data were analysed with two statistical programs: SPSS 25 (IBM SPS Statistics, Armonk, New York, USA) and Sigma Plot 11 (Systat Software GmbH, Erkrath, Germany).

\section{Results}

The ability to detect the following mosquito-borne pathogens prevalent in SSA was determined: Plasmodium sp., DENV, WNV, ZIKV, YFV, SFV, ONNV, CHIKV and RVFV. The selected primer pairs listed in Table 2 were first tested in a singleplex PCR and then used in a nineplex-RT-PCR, to detect a positive control. Gel electrophoresis documented that each targeted pathogen could be detected and amplified; the sizes of the PCR products of a single multiplex-RT-PCR run are shown in Fig. 2. The 
Table 3 Multiplex-RT-PCR-ELISA positive controls

\begin{tabular}{|c|c|c|c|c|c|}
\hline & Family & No & Pathogen & Source & Positive control \\
\hline \multirow[t]{8}{*}{ Arbo viruses } & Flaviviridae & 1 & Dengue virus (DENV) & $\begin{array}{l}\text { Laboratory of Pediatric Immunol- } \\
\text { ogy and Infectious Diseases, } \\
\text { Mainz, Germany }\end{array}$ & $\begin{array}{l}\text { Inactivated particles: DENV sero- } \\
\text { types 1, 2, } 3 \text { and } 4\end{array}$ \\
\hline & & 2 & West Nile virus (WNV) & $\begin{array}{l}\text { HiSS Diagnostics GmbH, Freiburg } \\
\text { im Breisgau, Germany }\end{array}$ & $\begin{array}{l}\text { Inactivated cell culture supernatant: } \\
\text { Accu Type TM West Nile virus } \\
\text { lineage I }\end{array}$ \\
\hline & & 3 & Zika virus (ZIKV) & $\begin{array}{l}\text { Robert Koch Institute, Berlin, } \\
\text { Germany }\end{array}$ & $\begin{array}{l}\text { Inactivated cell culture supernatant } \\
\text { (strain MR766-infected Vero E6 } \\
\text { cells); aliquoted and freeze-dried }\end{array}$ \\
\hline & Togaviridae (Alphaviruses) & 4 & Yellow Fever virus (YFV) & $\begin{array}{l}\text { Robert Koch Institute, Berlin, } \\
\text { Germany }\end{array}$ & Inactivated cell culture supernatant \\
\hline & & 5 & Semliki Forest virus (SFV) & $\begin{array}{c}\text { European Virus Archive goes } \\
\text { Global, Marseille, France }\end{array}$ & $\begin{array}{l}\text { Original isolate. RNA prepared from } \\
\text { cell culture supernatant using } \\
\text { QIAamp Viral RNA Mini Kit, Qiagen }\end{array}$ \\
\hline & & 6 & O'nyong-nyong virus (ONNV) & $\begin{array}{l}\text { European Virus Archive goes } \\
\text { Global }\end{array}$ & $\begin{array}{l}\text { Inactivated cell culture supernatant } \\
\text { (strain Dakar 234-infected Vero } \\
\text { cells); freeze-dried sample }\end{array}$ \\
\hline & & 7 & Chikungunya virus (CHIKV) & $\begin{array}{l}\text { Institut for Virology- Universitätsk- } \\
\text { linikum, Freiburg, Germany }\end{array}$ & Inactivated virus particles \\
\hline & Bunyaviridae & 8 & Rift Valley Fever virus (RVFV) & $\begin{array}{l}\text { Robert Koch Institute, Berlin, } \\
\text { Germany }\end{array}$ & Inactivated cell culture supernatant \\
\hline Protozoa & Malaria (Plasmodium sp.) & 9 & $\begin{array}{l}\text { P. falciparum } \\
\text { P. vivax } \\
\text { P. malariae }\end{array}$ & $\begin{array}{l}\text { Discovery Life Sciences, Los Osos, } \\
\text { CA, USA }\end{array}$ & $\begin{array}{l}\text { Serum obtained from patients with } \\
\text { acute malaria infection ( } P \text {. falci- } \\
\text { parum, } P \text {. vivax, and } P \text {. malariae). } \\
\text { Microscopy results: parasite- } \\
\text { positive }\end{array}$ \\
\hline
\end{tabular}

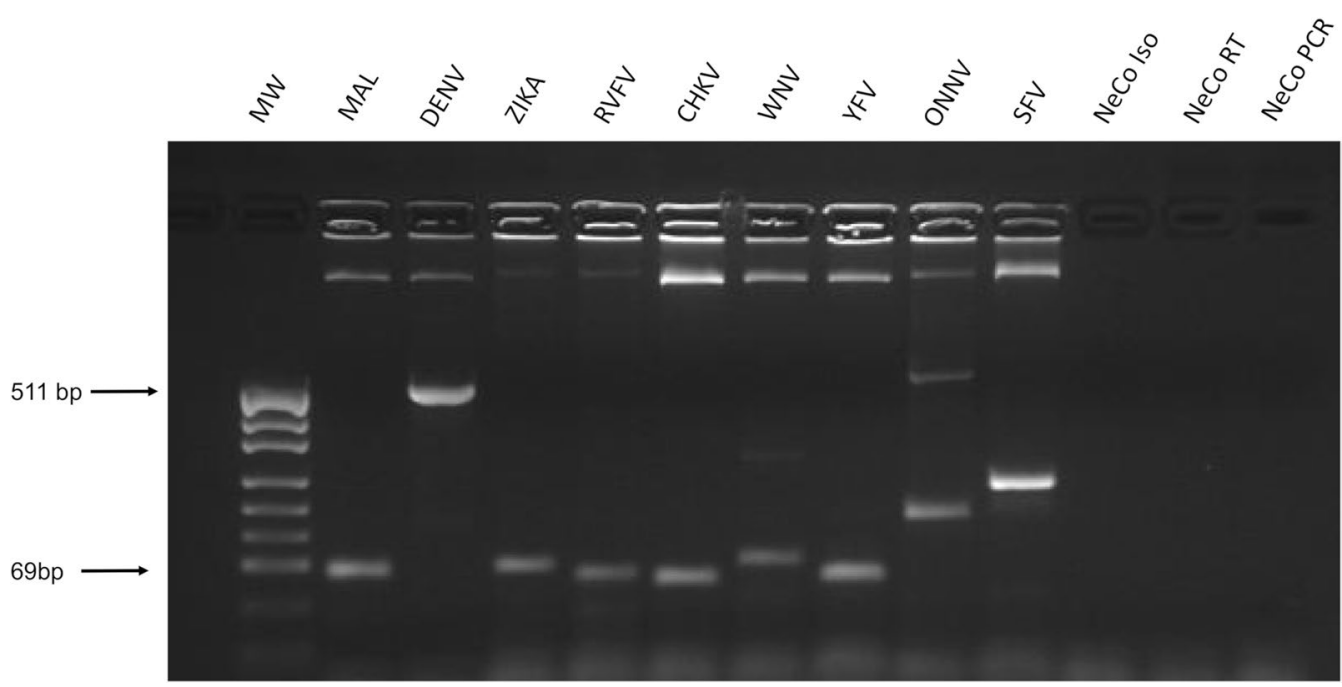

Fig. 2 Gel electrophoresis of multiplex-RT-PCR products. The nucleic acid isolated from each of nine vector-borne pathogens (positive controls) was amplified using the multiplex-RT-PCR, and the product of each reaction was subjected to $2 \%$ agarose gel electrophoresis. MW molecular weight marker pUC19 DNA/Mspl, ThermoFisher Scientific, Waltham, MA USA) and the following pathogens, MAL malaria, 99 bp, DENV Dengue virus, 511 bp, ZIKA Zika virus, 100 bp, RVFV Rift Valley Fever virus, 69 bp, CHIKV Chikungunya virus, 81 bp, WNVWest Nile virus, 116 bp, YFV Yellow Fever virus (YFV 83 bp), ONNV O'nyong-nyong virus, 148 bp, SFV Semliki Forest virus, 230 bp, NeCo Iso negative isolation control, NeCo RT negative reverse transcriptase control, NeCo $P C R$ negative primermix control 
occurrence of unspecific bands underline that pathogens could not be differentiated based solely upon the size of the PCR product, necessitating analysis of the PCR products by hybridization with targeted, 3 'biotinylated capture probes. The probes hybridized only with the multiplex-RT-PCR product (amplicon) of the positive control for which they were specific and meant to target. Hybridization with the amplicons generated from negative and unrelated positive controls was negligible. The resulting, normalized OD values are shown in Table 4. All OD values measured for the amplicons of the respective positive control were highly significant $(\geq 0.4 \mathrm{OD})$. These findings evidence that each sequence was amplified specifically, and no cross-contamination occurred. Plasmodium sp. (P. falciparum, $P$. vivax and P. malariae) were differentiated using a multiplex-RT-PCR that recognized the three species in positive sera derived from different patients with acute malaria infections (Fig. 3). DENV-serotyping on inactivated viral particles was performed by singleplex PCR following Chien et al. [25].

\section{Evaluation of sensitivity}

The ability of the multiplex-RT-PCR-ELISA panel to detect ZIKV RNA serially diluted from $1: 10^{6}$ to $1: 10^{1}$ copies/ml was determined in order to establish the limits of multiplex-RT-PCR sensitivity (Table 5). One thousand copies/ml was the limit of ZIKV RNA detection. ODvalues considered borderline were only classified as positive or negative after retesting. Therefore, the sensitivity limit of the nine-valent, multiplex-RT-PCR-ELISA can be assumed to be up to 1000 copies of pathogen nucleic acid per ml. Detection limits were only determined for ZIKV; the concentration of viral RNA in the positive controls for the other arboviruses was not known. All OD-values were quantified in a single microwell-plate negating any need to normalize.

\section{Extraction of positive controls from sample cards}

The six paper disks derived from positive controls spotted on sample cards were eluted by 3 different elution methods described above. After incubation, the eluate was transferred into a new reaction tube, the nucleic acid was extracted, and multiplex-RT-PCR-ELISA was performed. According to the optical density values derived, six out of eight vector-borne pathogens extracted by the method of Klüber (Master's Thesis, unpublished) using nuclease-free water were reliably detected (Tables 6, 7). The method of Grüner and co-workers [17] and a combination of the Klüber and Grüner methods could only extract four out of eight pathogens from sample cards (Table 6; Fig. 4a, b).

\section{Preservation capacity of Whatman ${ }^{\circledR} 903$ protein sample cards}

The capacity of Whatman ${ }^{\circledR} 903$ protein sample cards to preserve samples obtained from 132 children admitted to the paediatric ward at BMC with a suspected Plasmodium infection depended upon the nature of the sample. DSS exhibited a $59.3 \%$ (95\% CI [0.388-0.776]) preservation rate detected by multiplex-RT-PCR-ELISA performed on the eluate extracted from cards and 97.1\% (95\% CI [0.919-0.994]) specificity (Table 8). The preservation rate for DBS, on the other hand, was $100 \%$ (95\% CI [0.872-1]) and the specificity was $98.1 \%$ (95\% CI [0.933$0.998]$ ). The consistency among preservation methods was excellent for whole blood spotted on sample cards (Cohen's kappa statistic), but only good for serum samples on cards [32].

\section{Preservation and analysis of clinical samples}

Blood samples, obtained from the 132 children referenced in the preceding paragraph, were spotted onto sample cards and dried for at least $24 \mathrm{~h}$ before storage under dry conditions; the duration of storage was 186 to 312 days (267 days median). Sera samples, mRDT test results, DBS and DSS samples were obtained from all 132 included patients. 122 blood smear results of the included patients could be obtained at BMC. In 10/132 cases blood smear evaluation was not performed or test results were not available.

Twenty-seven out of 132 patients' sera were tested positive for Plasmodium sp. by multiplex-RT-PCR-ELISA. Following the above described extraction method, consequently 27/132 DBS and 19/132 DSS samples were found positive for Plasmodium sp. by multiplex-RT-PCRELISA. Each positive sample was confirmed by singleplex-PCR. 13.9\% (17/122) of the blood smear tests had a positive finding for malaria parasites. The RDT from NADAL ${ }^{\circledR}$ found twenty-eight out of 132 blood samples positive for Plasmodium sp. antigens.

\section{Table 4 Multiplex-RT-PCR-ELISA}

\begin{tabular}{|c|c|c|c|c|c|c|c|c|c|}
\hline Positive control & P. fal & DENV $^{a}$ & ZIKA & RVFV & CHIKV & WNV & YFV & ONNV & SFV \\
\hline ELISA $^{\mathrm{b}}\left(\mathrm{OD}_{405}\right)$ & $2.31 \pm 0.01$ & $1.65 \pm 0.07$ & $2.12 \pm 0.05$ & $1.72 \pm 0.09$ & $1.27 \pm 0.04$ & $1.67 \pm 0.11$ & $2.04 \pm 0.08$ & $1.77 \pm 0.07$ & $1.92 \pm 0.20$ \\
\hline
\end{tabular}



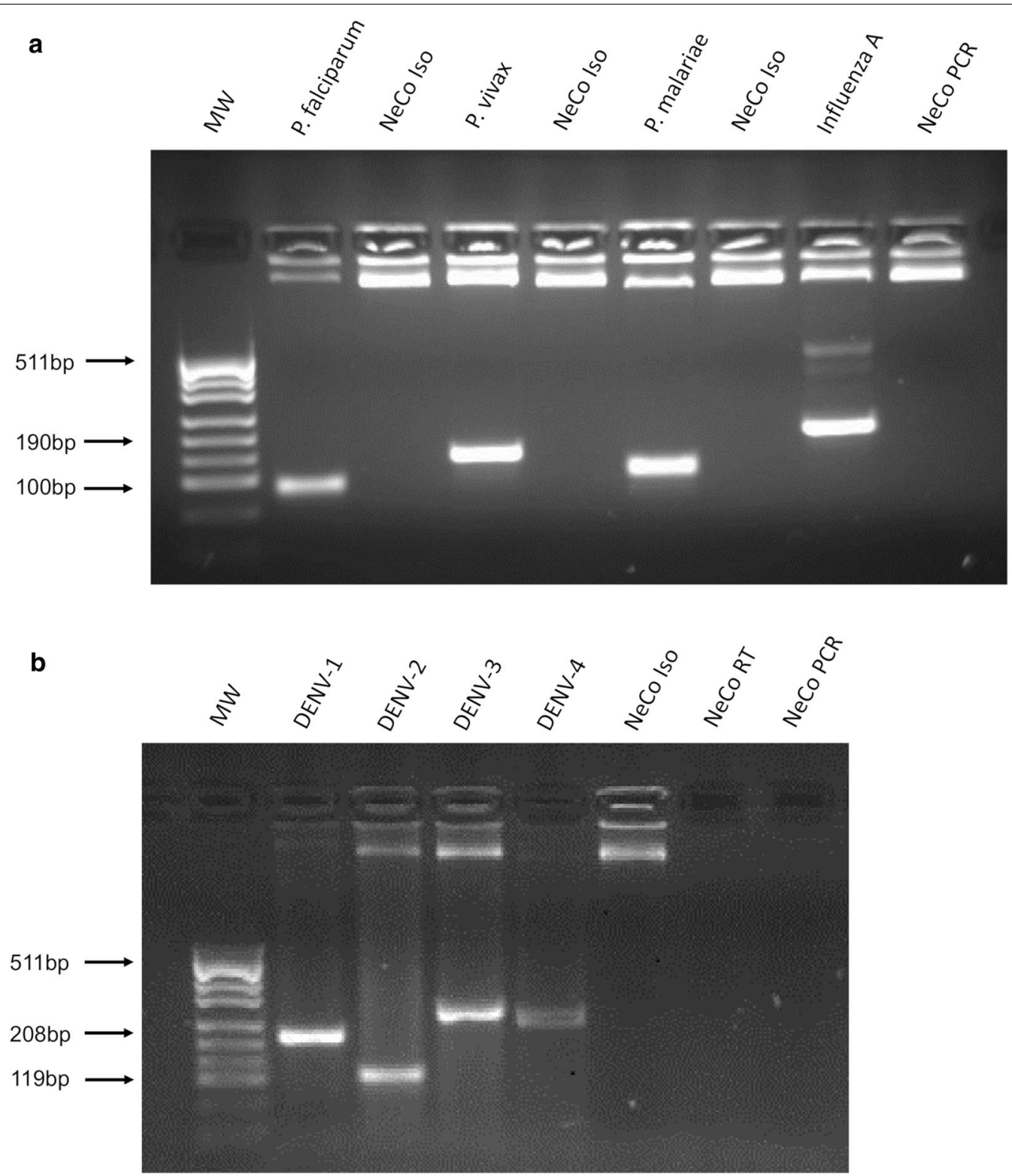

Fig. 3 Differentiation of Plasmodium sp. and DENV serotypes. Plasmodium falciparum, P. vivax and P. malariae in species-positive sera derived from infected patients were amplified by multiplex-RT-PCR and then differentiated by $2 \%$ agarose gel electrophoresis (a). Inactivated DENV particles were amplified and serotyped by singleplex PCR (b). MW molecular weight marker pUC19 DNA/Mspl and the following species or serotypes: P. falciparum, 100 bp; P. vivax, 141 bp; P. malariae, 166 bp; DENV-1, 208 bp; DENV-2, 119 bp; DENV-3, 288 bp; and DENV-4, 260 bp; Influenza A, 190 bp served as a positive control; $\mathrm{NaCl}$ and nuclease-free $\mathrm{H}_{2} \mathrm{O}$ served as negative isolation ( $\mathrm{NeCO}$ Iso) and primer mix controls (NeCo PCR), respectively

Table 5 Multiplex-RT-PCR-ELISA detection limit Zika-Virus ${ }^{\mathrm{a}}$

\begin{tabular}{llllllll}
\hline Virus RNA copies/ml & $\mathbf{1} \times \mathbf{1 0}^{\mathbf{6}}$ & $\mathbf{1 \times 1 0 ^ { \mathbf { 5 } }}$ & $\mathbf{1 \times 1 0 ^ { \mathbf { 4 } }}$ & $\mathbf{1 \times 1 0 ^ { \mathbf { 3 } }}$ & $\mathbf{1 \times 1 0 ^ { \mathbf { 2 } }}$ & $\mathbf{1 \times 1 0 ^ { \mathbf { 1 } }}$ & $\mathbf{1 \times 1 0 ^ { \mathbf { 0 } }}$ \\
\hline $\mathrm{ELISA}^{\mathrm{b}}\left(\mathrm{OD}_{405}\right)$ & $1.45 \pm 0.05$ & $1.55 \pm 0.19$ & $1.06 \pm 0.17$ & $0.41 \pm 0.11$ & $0.17 \pm 0.13$ & $0.09 \pm 0.01$ & $0.09 \pm 0.03$
\end{tabular}

${ }^{a}$ The MR766 strain of ZIKV $\left(1 \times 10^{7}\right.$ viral RNA copies/ml) was serially diluted 1:10 and multiplex-RT-PCR-ELISA was conducted to determine the limits of detection b Values are the means \pm SEM calculated from 3 determinations. OD readings $\geq 4$-times the negative control $\left(0.1 \mathrm{OD}_{405}\right)$ were judged positive $[27]$. Values 2 - to 4 -times the negative control were considered borderline 
Table 6 Efficacy of multiplex-RT-PCR-ELISA conducted on positive controls eluted from sample cards

\begin{tabular}{|c|c|c|c|c|c|c|c|}
\hline Pathogens ${ }^{\mathrm{a}}$ & P. fal & DENV & ZIKA & RVF & CHIKV & WNV & YFV \\
\hline $\begin{array}{l}\text { Spotted } \\
\text { ELISA }\left(\mathrm{OD}_{405}\right)\end{array}$ & 0.77 & 0.59 & 0.42 & 1.49 & 0.59 & 0.38 & 1.32 \\
\hline $\begin{array}{l}\text { Not spotted } \\
\text { ELISA }\left(\mathrm{OD}_{405}\right)\end{array}$ & 2.31 & 1.65 & 2.12 & 1.72 & 1.27 & 1.67 & 2.04 \\
\hline
\end{tabular}

a The positive controls listed were spotted onto sample cards, eluted by the method of Klüber (unpublished Master's Thesis) and quantified by multiplex-RT-PCRELISA. Multiplex-RT-PCR-ELISA conducted on the same controls not spotted onto cards serves as positive controls. All results were normalized in terms of pooled influenza A amplicons (20 $\mathrm{\mu l} /$ well) added to the microtiter plates

Table 7 Efficacy of multiplex-RT-PCR-ELISA conducted on positive controls eluted from sample cards

\begin{tabular}{|c|c|c|c|c|c|c|c|}
\hline Pathogens $^{a}$ & P. fal & DENV & ZIKA & RVF & CHIKV & WNV & YFV \\
\hline $\begin{array}{l}\text { Elution Klüber method } \\
\text { ELISA }\left(\mathrm{OD}_{405}\right)\end{array}$ & $0.77 \pm 0.1$ & $0.59 \pm 0.26$ & $0.42 \pm 0.25$ & $1.49 \pm 0.13$ & $0.59 \pm 0.24$ & $0.38 \pm 0.27$ & $1.32 \pm 0.54$ \\
\hline $\begin{array}{l}\text { Elution Klüber-Gruner method } \\
\text { ELISA }\left(\mathrm{OD}_{405}\right)\end{array}$ & $1.17 \pm 0.25$ & $0.41 \pm 0.04$ & $0.26 \pm 0.07$ & $1.44 \pm 0.42$ & $0.33 \pm 0.07$ & $0.33 \pm 0.1$ & $0.44 \pm 0.23$ \\
\hline $\begin{array}{l}\text { Elution Gruner method } \\
\text { ELISA }\left(\mathrm{OD}_{405}\right)\end{array}$ & $0.6 \pm 0.14$ & $0.3 \pm 0.02$ & $0.25 \pm 0.02$ & $0.8 \pm 0.1$ & $0.24 \pm 0.04$ & $0.23 \pm 0.04$ & $0.47 \pm 0.24$ \\
\hline $\begin{array}{l}\text { Not spotted } \\
\text { ELISA }\left(\mathrm{OD}_{405}\right)\end{array}$ & $2.31 \pm 0.01$ & $1.65 \pm 0.07$ & $2.12 \pm 0.05$ & $1.72 \pm 0.09$ & $1.27 \pm 0.04$ & $1.67 \pm 0.11$ & $2.04 \pm 0.08$ \\
\hline
\end{tabular}

a Data, normalized based upon the $\mathrm{OD}_{405}$ values generated from pooled influenza A amplicons, are the means \pm SEM obtained from triplicate plates shown in Fig. 3 . $O D$ readings $\geq 4$-times the negative control $\left(0.1 \mathrm{OD}_{405}\right)$ were judged to be positive

The results of standard diagnostic test obtained at BMC were compared to those obtained by multiplexvalent-RT-PCR-ELISA. Microscopic examination of blood smears conducted at BMC lacked the sensitivity and specificity required to detect acute malaria infections (Table 9). The sensitivity and specificity of the mRDT NADAL $^{\circledR}$ and the multiplex-RT-PCR-ELISA, on the other hand, were approximately equal. Notably, the cause of high fever and malaria-like symptoms in the remaining paediatric patients found free of Plasmodium sp. was indeterminate; analysis of sera and DBS samples by multiplex-RT-PCR-ELISA failed to identify an aetiologic agent.

\section{Discussion}

The Department of Pediatric Immunology and Infectious Diseases at the University Mainz developed a multiplexRT-PCR-ELISA for the comprehensive, laboratory-based surveillance of pathogens that cause acute respiratory infections [28]. A previously reported multiplex-RT-PCR panel combined with a microwell hybridization assay (multiplex-RT-PCR-ELISA) allows the simultaneous detection of 19 respiratory pathogens [14]. The feasibility of the multiplex-RT-PCR-ELISA was tested on clinical specimens and validated for diagnosis of respiratory tract infections; tests on culture supernatants were comparable to gold standard references. Descriptive epidemiological studies based upon results obtained by this method have been reported [33]. More than 30,000 samples have been analysed since 1996.

Here, it was demonstrated that positive controls for nine vector-borne pathogens can be detected simultaneously by a multiplex-RT-PCR-ELISA panel. MultiplexRT-PCR-ELISA was tested with several replicates and found reproducible. 16 samples can be tested within around $10 \mathrm{~h}$ working time. This poses a major limitation implementing the multiplex-RT-PCR-ELISA into clinical routine of low-resource settings. The sensitivity limit of 1000 copies/ml is comparable with established multiplexRT-PCR-ELISA approaches looking for Zika, Dengue and Chikungunya viral infections in clinical samples in Nicaragua [34]. Serologic markers are a powerful alternative for epidemiologic research of vector-borne diseases but are of limited value in diagnosing arbovirus coinfections. Extensive antigenic cross-reactivity between arboviruses contributes to a lack of specificity [35-37]. Moreover, Plasmodium sp. triggered polyclonal B-lymphocyte activation during cases of malaria can lead to ambiguous serologic results [38-40].

Tanzania must be added to the list of countries where Plasmodium sp. and arboviruses are endemic, and coinfections are likely to occur [41, 42]. Diagnostic tools like multiplex-RT-PCR-ELISA can differentiate the pathogens that cause acute febrile disease and should be considered as an approach in countries where a wide variety of mosquito-borne diseases are prevalent. Multiplex-RTPCR-ELISA panels are easily expanded and modified, 

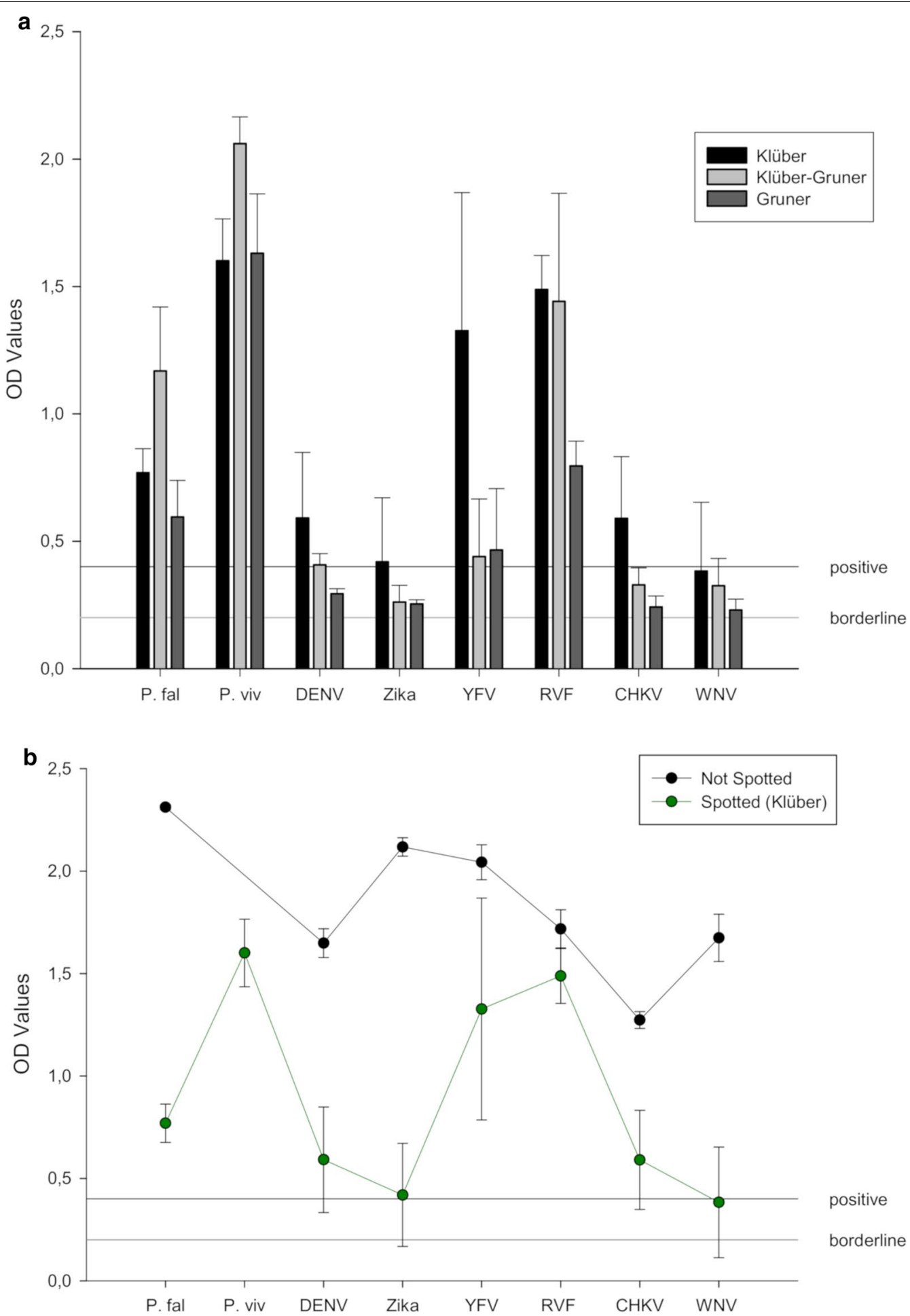

Fig. 4 Efficacy of sample card extraction. Sample cards spotted with the positive controls listed on the $x$-axis were extracted by one of three methods indicated in the Key (a). Positive controls were either not spotted or spotted on sample cards and eluted by the method of Klüber (unpublished) (b). In all cases, the positive control in the resultant sample was quantified by multiplex-RT-PCR-ELISA. OD-values are the means \pm standard deviation of triplicate determinations 
Table 8 Concordance rates of Plasmodium sp. spotted on cards

\begin{tabular}{|c|c|c|c|c|c|c|c|}
\hline \multirow[t]{2}{*}{ Sample card } & \multicolumn{2}{|c|}{ Concordant $^{\mathrm{a}}$} & \multicolumn{2}{|c|}{ Discordant $^{a}$} & \multirow[t]{2}{*}{$\%$ Concordance $^{\mathbf{b}}$} & & \multirow[t]{2}{*}{ Cohen's Kc } \\
\hline & $+/+$ & $-1-$ & \pm & $-1+$ & & & \\
\hline Sera, $n=132$ & $16 / 27$ & $102 / 105$ & 3/105 & $11 / 27$ & $89.39 \%$ & 0.634 & \\
\hline whole blood, $n=132$ & $27 / 27$ & $103 / 105$ & $2 / 105$ & $0 / 27$ & $98.48 \%$ & 0.955 & \\
\hline
\end{tabular}

Sera and whole blood samples obtained from 132 children suspected of having malaria were spotted onto cards. Subsequently, the spots were eluted by the method of Klüber (unpublished Master's Thesis) and quantified by multiplex-RT-PCR-ELISA

a Key: $+/+$, true positive; $-/-$, true negative; \pm , false positive; $-/+$, false negative

b Compared to the results of multiplex-RT-PCR-ELISA performed directly on the same, non-spotted patient sample

${ }^{c}$ Interrater reliability where $\mathrm{\kappa} 0.61-0.80=$ substantial agreement and $\mathrm{\kappa} 0.81-0.99=$ near perfect agreement

Table 9 Efficacy of standard diagnostic tools for detecting Plasmodium sp.

\begin{tabular}{lll}
\hline & Sensitivity (+/+) & Specificity (-/-) \\
\hline $\begin{array}{c}\text { Blood smear micros- } \\
\text { copy, } n=122\end{array}$ & $40.0 \%(10 / 25)$ & $92.8 \%(90 / 97)$ \\
$\left.\begin{array}{l}\text { mRDT }(\text { NADAL } \\
n=132\end{array}\right)$, & $96.3 \%(26 / 27)$ & $98.1 \%(103 / 105)$ \\
& &
\end{tabular}

The presence of Plasmodium sp. in blood samples obtained from 132 children suspected of having malaria was assessed by blood smear microscopy and $\mathrm{mRDT}$. The results were compared to those obtained for the same patient cohort that tested positive by multiplex-RT-PCR-ELISA, i.e., 27 of 132

and thereby adapted to current epidemiologic challenges. Arbovirus infections usually have a short viremic phase, lasting 5-7-days and preceding clinical symptoms. As such, there is a risk of collecting blood samples too late, causing false negative results and an underestimated prevalence of these pathogens. To overcome this limitation, specific serologic tests capable of distinguishing precisely between different flaviviruses might be a reasonable addition to determining the prevalence of arboviruses in SSA-regions [43]. Still, alphaviruses like CHIKV and ONNV remain a diagnostic challenge in terms of detection with serological methods.

Microscopic examination of blood smears is the standard diagnostic approach for suspected cases of malaria at tertiary health facilities, such as BMC. Only $21 \%$ of the presumptive malaria cases in the presented cohort could be confirmed by multiplex-RT-PCR-ELISA or the RDT. Incongruent malaria diagnostics reveal a significant limitation in daily clinical routine. RDT NADAL ${ }^{\circledR}$ exhibited $96 \%$ sensitivity in detecting acute malaria infections and was very specific (98\%). In contrast, examination of blood smear performed at BMC detected only 4 out of 10 cases of malaria. These findings underline how diagnostic approaches with low sensitivity performance lead to misassumption of malaria cases. Studies conducted in Northern Tanzania concluded that using microscopy testing malaria is over-diagnosed and malaria-like febrile illnesses caused by other mosquito-borne pathogens such as CHIKV are underestimated [44]. Parallelly, microscopy of blood films misses clinically relevant cases of low-density parasitaemia [45-47]. The RDT has proven to be highly accurate and cost-effective for the Tanzanian government [3]. Significant discrepancies in the results of diagnostic tests for malaria (i.e., blood smear microscopy and RDT versus genus-specific PCR) were documented in Dar es Salaam, Tanzania [48]. Remarkably, NADAL ${ }^{\circledR}$ RDT used in the study reported herein showed greater sensitivity than did Paracheck-Pf ${ }^{\circledR}$ RDT compared to RT-PCR as the gold standard in similar studies [49]. The data reported herein should provide a rational approach for the targeted use of anti-malarials and antibiotics, thus reducing the potential overuse of both medications. Notably, the WHO goal of "keeping artemisinin-based drugs an effective treatment against malaria infections" (2011) correlates with this objective [50].

A wide range of vector-borne pathogens spotted on sample cards, including Plasmodium sp., DENV, YFV, RVF and CHIKV, was detected by multiplex-RT-PCRELISA. A variety of factors, e.g., storage conditions such as temperature and humidity, can influence the capacity of these cards to preserve vector-borne pathogens. Extraction with nuclease-free water optimized recovery of material in DBS from sample card in the study reported herein. This finding correlates with results of other investigators who reported the highest yield of DENV-positive clinical specimens spotted on sample cards was obtained by nuclease-free water extraction [51]. Indeed, nucleasefree water is already used for extracting DENV antibodies from DSS [52]. However, while extraction at a high temperature $\left(72{ }^{\circ} \mathrm{C}\right)$ favoured recovery of nucleic acids from samples spotted on cards in our study, such high temperatures would limit recovery of antibodies for subsequent diagnostic tests. Moreover, ZIKV and WNV spotted onto sample cards in the study reported here were not readily extracted in nuclease-free water at $72{ }^{\circ} \mathrm{C}$ and quantified, indicating the obligate need to conduct additional studies to maximize the recovery of a diverse pathogen population and its components spotted on sample cards. 
In 2012, the WHO declared a global strategy to reduce the burden of vector-borne pathogens like DENV by 2020 [53]. A systematic literature review of DENV infections in Tanzania concluded that DENV is endemic and must be regarded as a relevant health issue [8]. Herein, it was documented that Whatman ${ }^{\circledR} 903$ protein sample cards represent a feasible approach to collecting presumptive, vector-borne disease samples, especially in rural areas. The degree to which specimens were preserved on sample cards differed significantly dependent upon the nature of the sample. Only $\sim 60 \%$ of Plasmodium-positive samples were preserved and recovered from DSS; all positive samples preserved as DBS, however, could be detected by multiplex-RT-PCR-ELISA. Similarly, Prado et al. reported the same discordant preservation of DENV-positive specimens eluted from cards and quantified by PCR, i.e., $100 \%$ specificity for DBS and only $47 \%$ for DSS [51].

Grüner et al. recommended storing DBS samples at room temperature for up to 2 weeks [17]. Remarkably, the data obtained in the present study indicates that the capacity to store Plasmodium sp. on sample cards could exceed 10 months, confirming the report of other investigators concerning the extended storage capacity of sample cards [54]. The ability to preserve viral components such as RNA at room temperature under dry conditions for a long period of time makes DBS on sample cards an extremely suitable method for preserving diagnostic specimens under challenging conditions. Establishment of DBS-based, multiplex-PCR-ELISA in referring SSA centres would simplify storage conditions and enable transport of samples to laboratories which are properly equipped for testing. An additional advantage of DBS is that only small quantities of blood are needed, a tremendous benefit when testing children.

Models, which consider the influence of climate on the distribution of vector habitats in the future, warn that outbreaks of arbovirus infections will increase in Tanzania within the next few years [55]. The Lake Victoria Region was identified as an area at risk [56]. Systematic surveillance would enable the early detection of arbovirus outbreaks and simplify therapeutic approaches, e.g., antipyretics, fluids or transfusion of blood components. Consequently, DBS and blood sample testing should continue in the Lake Victoria Region. Future aspects of epidemiologic research should also consider improved methods to extract and analyse serologic markers from sample cards $[52,57]$.

\section{Conclusions}

Point of care diagnostic tests comprise a promising area of research that has proven to reduce the prescription of non-indicated antibiotics and anti-Plasmodium drugs to children with acute, febrile diseases in Tanzania that are unrelated to malaria [58]. Indeed, smart ELISA platforms, which are capable of detecting serologic markers of DENV-infections, exhibit up to $95 \%$ sensitivity in clinical settings [59]. Unfortunately, the multiplex-RT-PCR-ELISA developed for the present study failed to determine the cause of malarialike symptoms in our paediatric patient cohort found free of Plasmodium sp. The cyclic nature of arboviral prevalence, fluctuating between outbreaks and low endemicity, and the time gap between viremia and clinical manifestation could be factors contributing to the absence of arboviruses in the data presented. Additionally, other common causes of acute fever such as viral respiratory tract infections, gastrointestinal infections, urinary tract infections and typhoid fever were not surveyed. As a consequence, the long-term goal of the present study is to continue monitoring and identifying the distribution of mosquito-transmittable pathogens most prevalent in SSA by multiplex-RT-PCR-ELISA. Once this is achieved, improved PCR-techniques such as loop mediated isothermal amplification (LAMP) will pave the way to well-targeted, robust and easy-to-use testing tools [60].

\section{Abbreviations \\ ARI: Acute respiratory infection; BMC: Bugando Medical Centre; CHIKV: Chi- kungunya virus; Cl: Confidence interval; CUHAS: Catholic University of Health and Allied Sciences; DBS: Dried blood spots; DSS: Dried serum spot; DENV: Dengue virus; ELISA: Enzyme-linked immunosorbent assay; HBV: Hepatitis B virus; HCV: Hepatitis C virus; HIV: Human immunodeficiency virus; RDT: Malaria rapid diagnostic test; RT-PCR: Reverse transcriptase-polymerase chain reaction; NIMR: National Institute of Medical Research; ONNV: O'nyong nyong virus; RVFV: Rift Valley fever virus; SFV: Semliki forest virus; SSA: Sub-Saharan Africa; WHO: World Health Organization; WNV: West Nile virus; YFV: Yellow fever virus; ZIKV: Zika virus.}

\section{Acknowledgements}

We are grateful to Dr. Stephen H. Gregory (Providence, RI, USA) for his help in writing and editing this manuscript.

\section{Authors' contributions}

PK designed the study, led the analysis, developed methods, maintained research data and drafted the manuscript. NMK supervised the data collection process in Tanzania. TD, FH, JK, and GCMM developed methods, collected research data, and performed experiments and statistical analysis. BG supervised laboratory research and developed methods. LP provided study materials and equipment. CS and AZ mentored investigators and established collaboration between BMC and the German Tropical Paediatric Society. SU provided and performed serologic analysis. SEM supervised investigation and ethical consideration. MA planned research activity. SG supervised and planned research activity and maintained project administration. All authors contributed to the manuscript. All authors read and approved the final manuscript.

\section{Funding}

Open Access funding enabled and organized by Projekt DEAL. This study was supported by the European Virus Archive goes Global project, which received funding from the European Union's Horizon 2020 research and innovation programme under grant agreement No. 653316. The project was partially funded by the Else-Kröner Fresenius Stiftung Klinikpartnerschaften (Bad Homburg, Germany) Grant No. 1601079. 


\section{Availability of data and materials}

The datasets used and/or analysed during the current study are available from the corresponding author on reasonable request.

\section{Ethics approval and consent to participate}

Ethical clearance (CREC/109/2016) for the use of sera and DBS-derived specimens was obtained from a Joint CUHAS/BMC ethics review committee of the Catholic University of Health and Allied Sciences (CUHAS) and Bugando Medical Centre (BMC). Ethical approval of the study was also obtained from the National Institute of Medical Research (NIMR) of Tanzania (NIMR/HQ/R.8a/ Vol.IX/2641) including Data and Material Transfer Agreements.

\section{Consent for publication}

Informed written consent was obtained from a parent or guardian of each child enrolled in the study.

\section{Competing interests}

The authors declare that they have no competing interests.

\begin{abstract}
Author details
${ }^{1}$ Center of Pediatric and Adolescent Medicine, University Medical Center, Mainz, Germany. ${ }^{2}$ Department of Pediatric and Adolescent Medicine, Bugando Medical Centre, Mwanza, Tanzania. ${ }^{3}$ Department of Microbiology and Immunology, Catholic University of Health and Allied Sciences, Mwanza, Tanzania. ${ }^{4}$ Department of Pediatric and Adolescent Medicine, St. Vinzenz-Hospital, Dinslaken, Germany. ${ }^{5}$ Fraunhofer Institute for Cell Therapy and Immunology, Leipzig, Germany. ${ }^{6}$ Department of Infectiology and Tropical Medicine, University Medical Center Hamburg-Eppendorf, Eppendorf, Germany. ${ }^{7}$ Department of Infection and Immunity, Luxembourg Institute of Health, Esch-sur-Alzette, Luxembourg.
\end{abstract}

Received: 9 November 2020 Accepted: 15 January 2021

Published online: 01 February 2021

\section{References}

1. WHO. World Malaria Report 2018. Geneva: World Health Organization; 2018.

2. D'Acremont V, Lengeler C, Genton B. Reduction in the proportion of fevers associated with Plasmodium falciparum parasitaemia in Africa: a systematic review. Malar J. 2010;9:240.

3. Harchut K, Standley C, Dobson A, Klaassen B, Rambaud-Althaus C, Althaus F, et al. Over-diagnosis of malaria by microscopy in the Kilombero Valley, Southern Tanzania: an evaluation of the utility and cost-effectiveness of rapid diagnostic tests. Malar J. 2013;12:159.

4. Bruxvoort KJ, Leurent B, Chandler CIR, Ansah EK, Baiden F, Bjorkman A, et al. The impact of introducing malaria rapid diagnostic tests on fever case management: a synthesis of ten studies from the ACT Consortium. Am J Trop Med Hyg. 2017;97:1170-9.

5. Rezza G. Dengue and chikungunya: long-distance spread and outbreaks in naive areas. Pathog Glob Health. 2014;108:349-55.

6. Brady OJ, Gething PW, Bhatt S, Messina JP, Brownstein JS, Hoen AG, et al. Refining the global spatial limits of dengue virus transmission by evidence-based consensus. PLoS Negl Trop Dis. 2012;6:e1760.

7. WHO. Weekly bulletin on outbreaks and other emergencies; Week 12. Geneva: World Health Organization; 2018.

8. Ward T, Samuel M, Maoz D, Runge-Ranzinger S, Boyce R, Toledo J, et al. Dengue data and surveillance in Tanzania: a systematic literature review. Trop Med Int Health. 2017;22:960-70.

9. Herlihy JM, D'Acremont V, Hay Burgess DC, Hamer DH. Diagnosis and treatment of the febrile child. In: Black RE, Laxminarayan R, Temmerman M, Walker N, Eds. Reproductive, Maternal, Newborn, and Child Health: Disease Control Priorities, 3rd Edn. Vol. 2. Washington (DC), The World Bank, 2016.

10. Shepard DS, Undurraga EA, Betancourt-Cravioto M, Guzman MG, Halstead SB, Harris E, et al. Approaches to refining estimates of global burden and economics of dengue. PLoS Negl Trop Dis. 2014;8:e3306.

11. Angelini R, Finarelli AC, Angelini P, Po C, Petropulacos K, Silvi G, et al. Chikungunya in north-eastern Italy: a summing up of the outbreak. Euro Surveill. 2007;12(E071122):2.
12. Paty MC. [Dengue fever in mainland France](in French). Arch Pediatr. 2014;21:1274-8.

13. Papa A. Emerging arboviral human diseases in Southern Europe. J Med Virol. 2017:89:1315-22.

14. Puppe W, Weigl J, Grondahl B, Knuf M, Rockahr S, von Bismarck P, et al. Validation of a multiplex reverse transcriptase PCR ELISA for the detection of 19 respiratory tract pathogens. Infection. 2013;41:77-91.

15. Mishra B, Sharma M, Pujhari SK, Ratho RK, Gopal DS, Kumar CN, et al. Utility of multiplex reverse transcriptase-polymerase chain reaction for diagnosis and serotypic characterization of dengue and chikungunya viruses in clinical samples. Diagn Microbiol Infect Dis. 2011;71:118-25.

16. Pabbaraju K, Wong S, Gill K, Fonseca K, Tipples GA, Tellier R. Simultaneous detection of Zika, Chikungunya and Dengue viruses by a multiplex realtime RT-PCR assay. J Clin Virol. 2016;83:66-71.

17. Grüner N, Stambouli O, Ross RS. Dried blood spots-preparing and processing for use in immunoassays and in molecular techniques. J Vis Exp. 2015;97:52619.

18. Anders KL, Nguyet NM, Quyen NTH, Ngoc TV, Tram TV, Gan TT, et al. An evaluation of dried blood spots and oral swabs as alternative specimens for the diagnosis of dengue and screening for past dengue virus exposure. Am J Trop Med Hyg. 2012;87:165-70.

19. Andriamandimby SF, Heraud JM, Randrianasolo L, Rafisandratantsoa JT, Andriamamonjy S, Richard V. Dried-blood spots: a cost-effective field method for the detection of Chikungunya virus circulation in remote areas. PLoS Negl Trop Dis. 2013;7:e2339.

20. Zainabadi K, Nyunt MM, Plowe CV. An improved nucleic acid extraction method from dried blood spots for amplification of Plasmodium falciparum kelch13 for detection of artemisinin resistance. Malar J. 2019;18:192.

21. WHO. Manual for HIV drug resistance testing using dried blood spot specimens. Geneva: World Health Organization; 2012.

22. WHO. First WHO Global Forum on Medical Devices: context, outcomes and future actions. Geneva: World Health Organization; 2011.

23. Matheus S, Huc P, Labeau B, Bremand L, Enfissi A, Merle O, et al. The use of serum spotted onto filter paper for diagnosing and monitoring Chikungunya virus infection. J Clin Virol. 2015;71:89-92.

24. WHO. Guidelines for the treatment of malaria. 3rd Edn. Geneva: World Health Organization; 2015.

25. Chien LJ, Liao TL, Shu PY, Huang JH, Gubler DJ, Chang GJ. Development of real-time reverse transcriptase PCR assays to detect and serotype dengue viruses. J Clin Microbiol. 2006;44:1295-304.

26. Kamau E, Tolbert LS, Kortepeter L, Pratt M, Nyakoe N, Muringo L, et al. Development of a highly sensitive genus-specific quantitative reverse transcriptase real-time PCR assay for detection and quantitation of Plasmodium by amplifying RNA and DNA of the 18S rRNA genes. J Clin Microbiol. 2011;49:2946-53.

27. Puppe W, Weigl JA, Aron G, Grondahl B, Schmitt HJ, Niesters HG, et al. Evaluation of a multiplex reverse transcriptase PCR ELISA for the detection of nine respiratory tract pathogens. J Clin Virol. 2004;30:165-74.

28. Grondahl B, Puppe W, Hoppe A, Kuhne I, Weigl JA, Schmitt HJ. Rapid identification of nine microorganisms causing acute respiratory tract infections by single-tube multiplex reverse transcription-PCR: feasibility study. J Clin Microbiol. 1999;37:1-7.

29. Alemayehu S, Feghali KC, Cowden J, Komisar J, Ockenhouse CF, Kamau E. Comparative evaluation of published real-time PCR assays for the detection of malaria following MIQE guidelines. Malar J. 2013;12:277.

30. Aslanzadeh J. Preventing PCR amplification carryover contamination in a clinical laboratory. Ann Clin Lab Sci. 2004;34:389-96.

31. Byrt T. How good is that agreement? Epidemiology. 1996;7:561.

32. Landis JR, Koch GG. The measurement of observer agreement for categorical data. Biometrics. 1977;33:159-74.

33. Weigl JA, Puppe W, Meyer CU, Berner R, Forster J, Schmitt HJ, et al. Ten years' experience with year-round active surveillance of up to 19 respiratory pathogens in children. Eur J Pediatr. 2007;166:957-66.

34. Waggoner JJ, Gresh L, Mohamed-Hadley A, Ballesteros G, Davila MJ, Tellez $Y$, et al. Single-reaction multiplex reverse transcription PCR for detection of Zika, Chikungunya, and Dengue Viruses. Emerg Infect Dis. 2016;22:1295-7.

35. Hassing RJ, Leparc-Goffart I, Tolou H, van Doornum G, van Genderen PJ. Cross-reactivity of antibodies to viruses belonging to the Semliki forest serocomplex. Euro Surveill. 2010;15:19588. 
36. Lanciotti RS, Kosoy OL, Laven JJ, Velez JO, Lambert AJ, Johnson AJ, et al. Genetic and serologic properties of Zika virus associated with an epidemic, Yap State, Micronesia, 2007. Emerg Infect Dis. 2008;14:1232-9.

37. Weller N, Clowes P, Dobler G, Saathoff E, Kroidl I, Ntinginya NE, et al. Seroprevalence of alphavirus antibodies in a cross-sectional study in southwestern Tanzania suggests endemic circulation of chikungunya. PLoS Negl Trop Dis. 2014;8:e2979.

38. Banic DM, Viana-Martins FS, De Souza JM, Peixoto TD, Daniel-Ribeiro C. Polyclonal B-lymphocyte stimulation in human malaria and its association with ongoing parasitemia. Am J Trop Med Hyg. 1991;44:571-7.

39. Fesel C, Goulart LF, Silva Neto A, Coelho A, Fontes CJ, Braga EM, et al. Increased polyclonal immunoglobulin reactivity toward human and bacterial proteins is associated with clinical protection in human Plasmodium infection. Malar J. 2005;4:5.

40. Schwarz NG, Mertens E, Winter D, Maiga-Ascofare O, Dekker D, Jansen S, et al. No serological evidence for Zika virus infection and low specificity for anti-Zika virus ELISA in malaria positive individuals among pregnant women from Madagascar in 2010. PLoS ONE. 2017;12:e0176708.

41. Furuya-Kanamori L, Liang S, Milinovich G, Soares Magalhaes RJ, Clements AC, Hu W, et al. Co-distribution and co-infection of chikungunya and dengue viruses. BMC Infect Dis. 2016;16:84.

42. Chipwaza B, Mugasa JP, Selemani M, Amuri M, Mosha F, Ngatunga SD, et al. Dengue and Chikungunya fever among viral diseases in outpatient febrile children in Kilosa district hospital. Tanzania PLoS Negl Trop Dis. 2014;8:e3335.

43. Rockstroh A, Barzon L, Pacenti M, Palu G, Niedrig M, Ulbert S. Recombinant envelope-proteins with mutations in the conserved fusion loop allow specific serological diagnosis of dengue-infections. PLoS Negl Trop Dis. 2015;9:e0004218.

44. Crump JA, Morrissey AB, Nicholson WL, Massung RF, Stoddard RA, Galloway RL, et al. Etiology of severe non-malaria febrile illness in Northern Tanzania: a prospective cohort study. PLoS Negl Trop Dis. 2013;7:e2324.

45. Katrak S, Nayebare P, Rek J, Arinaitwe E, Nankabirwa JI, Kamya M, et al. Clinical consequences of submicroscopic malaria parasitaemia in Uganda. Malar J. 2018;17:67.

46. Batwala V, Magnussen P, Nuwaha F. Are rapid diagnostic tests more accurate in diagnosis of Plasmodium falciparum malaria compared to microscopy at rural health centres? Malar J. 2010;9:349.

47. Bell DR, Wilson DW, Martin LB. False-positive results of a Plasmodium falciparum histidine-rich protein 2-detecting malaria rapid diagnostic test due to high sensitivity in a community with fluctuating low parasite density. Am J Trop Med Hyg. 2005;73:199-203.

48. Strom GE, Haanshuus CG, Fataki M, Langeland N, Blomberg B. Challenges in diagnosing paediatric malaria in Dar es Salaam. Tanzania Malar J. 2013;12:228.

49. Fancony C, Sebastiao YV, Pires JE, Gamboa D, Nery SV. Performance of microscopy and RDTs in the context of a malaria prevalence survey in Angola: a comparison using PCR as the gold standard. Malar J. 2013;12:284.

50. WHO. Global plan for artemisinin resistance containment - GPARC. Geneva: World Health Organization; 2011.

51. Prado I, Rosario D, Bernardo L, Alvarez M, Rodriguez R, Vazquez S, et al. PCR detection of dengue virus using dried whole blood spotted on filter paper. J Virol Methods. 2005;125:75-81.

52. Maldonado-Rodriquez A, Rojas-Montes O, Vazquez-Rosales G, ChavezNegrete A, Rojas-Uribe M, Posadas-Mondragon A, et al. Serum dried samples to detect dengue antibodies: a field study. Biomed Res Int. 2017; $2017: 7215259$

53. WHO. Global Strategy for dengue prevention and control, 2012-2020. Geneva: World Health Organization; 2012.

54. Chaorattanakawee S, Natalang O, Hananantachai H, Nacher M, Brockman A, Krudsood S, et al. Storage duration and polymerase chain reaction detection of Plasmodium falciparum from blood spots on filter paper. Am J Trop Med Hyg. 2003;69:42-4.

55. Mweya CN, Kimera SI, Stanley G, Misinzo G, Mboera LE. Climate change influences potential distribution of infected Aedes aegypti cooccurrence with dengue epidemics risk areas in Tanzania. PLoS ONE. 2016;11:e0162649.

56. Mweya CN, Mboera LEG, Kimera SI. Climate influence on emerging risk areas for rift valley fever epidemics in Tanzania. Am J Trop Med Hyg. 2017:97:109-14.
57. Smit PW, Elliott I, Peeling RW, Mabey D, Newton PN. An overview of the clinical use of filter paper in the diagnosis of tropical diseases. Am J Trop Med Hyg. 2014;90:195-210.

58. Keitel K, Kagoro F, Samaka J, Masimba J, Said Z, Temba H, et al. A novel electronic algorithm using host biomarker point-of-care tests for the management of febrile illnesses in Tanzanian children (e-POCT): A randomized, controlled non-inferiority trial. PLoS Med. 2017;14:e1002411.

59. Thiha A, Ibrahim F. A colorimetric enzyme-linked immunosorbent assay (ELISA) detection platform for a point-of-care dengue detection system on a lab-on-compact-disc. Sensors (Basel). 2015;15:11431-41.

60. Mohon AN, Getie S, Jahan N, Alam MS, Pillai DR. Ultrasensitive loop mediated isothermal amplification (US-LAMP) to detect malaria for elimination. Malar J. 2019;18:350

61. Konongoi L, Ofula V, Nyunja A, Owaka S, Koka H, Makio A, et al. Detection of dengue virus serotypes 1,2 and 3 in selected regions of Kenya: 2011-2014. Virol J. 2016;13:182

62. Vairo F, Mboera LE, De Nardo P, Oriyo NM, Meschi S, Rumisha SF, et al. Clinical, virologic, and epidemiologic characteristics of dengue outbreak, Dar es Salaam, Tanzania, Dar es Salaam, Tanzania, 2014. Emerg Infect Dis. 2016:22:895-9.

63. Vu DM, Banda T, Teng CY, Heimbaugh C, Muchiri EM, Mungai PL, et al. Dengue and West Nile Virus transmission in children and adults in coastal Kenya. Am J Trop Med Hyg. 2017;96:141-3.

64. Tigoi C, Lwande O, Orindi B, Irura Z, Ongus J, Sang R. Seroepidemiology of selected arboviruses in febrile patients visiting selected health facilities in the lake/river basin areas of Lake Baringo, Lake Naivasha, and Tana River. Kenya Vector Borne Zoonotic Dis. 2015;15:124-32.

65. Sule WF, Oluwayelu DO, Hernandez-Triana LM, Fooks AR, Venter M, Johnson N. Epidemiology and ecology of West Nile virus in sub-Saharan Africa. Parasit Vectors. 2018;11:414.

66. Kauffman EB, Jones SA, Dupuis AP 2nd, Ngo KA, Bernard KA, Kramer LD. Virus detection protocols for west nile virus in vertebrate and mosquito specimens. J Clin Microbiol. 2003:41:3661-7.

67. Posen HJ, Keystone JS, Gubbay JB, Morris SK. Epidemiology of Zika virus, 1947-2007. BMJ Glob Health. 2016;1:e000087.

68. Buechler CR, Bailey AL, Weiler AM, Barry GL, Breitbach ME, Stewart LM, et al. Seroprevalence of Zika virus in wild African green monkeys and baboons. mSphere. 2017;2:e00392-16.

69. Ahmed QA, Memish ZA. Yellow fever from Angola and Congo: a storm gathers. Trop Doct. 2017;47:92-6.

70. Yellow fever in Africa and the Americas, 2016. Wkly Epidemiol Rec. 2017:92(32):442-52.

71. Douam F, Ploss A. Yellow Fever Virus: Knowledge Gaps Impeding the Fight Against an Old Foe. Trends Microbiol. 2018;26:913-28.

72. Fernandes-Monteiro AG, Trindade GF, Yamamura AM, Moreira OC, de Paula VS, Duarte AC, et al. New approaches for the standardization and validation of a real-time QPCR assay using TaqMan probes for quantification of yellow fever virus on clinical samples with high quality parameters. Hum Vaccin Immunother. 2015;11:1865-71.

73. Puglia AL, Rezende AG, Jorge SA, Wagner R, Pereira CA, Astray RM. Quantitative RT-PCR for titration of replication-defective recombinant Semliki Forest virus. J Virol Methods. 2013;193:647-52.

74. Rezza G, Chen R, Weaver SC. O'nyong-nyong fever: a neglected mosquito-borne viral disease. Pathog Glob Health. 2017;111:271-5.

75. Marshall TF, Keenlyside RA, Johnson BK, Chanas AC, Smith DH. The epidemiology of O'nyong-nyong in the Kano Plain. Kenya Ann Trop Med Parasitol. 1982;76:153-8.

76. LaBeaud AD, Banda T, Brichard J, Muchiri EM, Mungai PL, Mutuku FM, et al. High rates of O'nyong nyong and Chikungunya virus transmission in coastal Kenya. PLoS Negl Trop Dis. 2015;9:e0003436.

77. Liu J, Ochieng C, Wiersma S, Stroher U, Towner JS, Whitmer S, et al. Development of a TagMan array card for acute-febrile-illness outbreak investigation and surveillance of emerging pathogens, including Ebola virus. J Clin Microbiol. 2016;54:49-58.

78. Kajeguka DC, Kaaya RD, Mwakalinga S, Ndossi R, Ndaro A, Chilongola JO, et al. Prevalence of dengue and chikungunya virus infections in northeastern Tanzania: a cross sectional study among participants presenting with malaria-like symptoms. BMC Infect Dis. 2016;16:183.

79. Pezzi L, Reusken CB, Weaver SC, Drexler JF, Busch M, LaBeaud AD, et al. GloPID-R report on Chikungunya, O'nyong-nyong and Mayaro virus, part I: Biological diagnostics. Antiviral Res. 2019;166:66-81. 
80. Panning M, Grywna K, van Esbroeck M, Emmerich P, Drosten C. Chikungunya fever in travelers returning to Europe from the Indian Ocean region, 2006. Emerg Infect Dis. 2008;14:416-22.

81. Heinrich N, Saathoff E, Weller N, Clowes P, Kroidl I, Ntinginya E, et al. High seroprevalence of Rift Valley fever and evidence for endemic circulation in Mbeya region, Tanzania, in a cross-sectional study. PLoS Negl Trop Dis. 2012;6:e1557.

82. Sumaye RD, Abatih EN, Thiry E, Amuri M, Berkvens D, Geubbels E. Interepidemic acquisition of Rift Valley fever virus in humans in Tanzania. PLoS Negl Trop Dis. 2015;9:e0003536.

83. D'Acremont V, Kilowoko M, Kyungu E, Philipina S, Sangu W, Kahama-Maro $J$, et al. Beyond malaria-causes of fever in outpatient Tanzanian children. N Engl J Med. 2014;370:809-17.

84. WHO. World Malaria Report 2016. Geneva: World Health Organization 2016

85. Kim MJ, Jung BK, Chai JY, Eom KS, Yong TS, Min DY, et al. High malaria prevalence among schoolchildren on Kome Island. Tanzania Korean J Parasitol. 2015:53:571-4.

86. Perandin F, Manca N, Calderaro A, Piccolo G, Galati L, Ricci L, et al. Development of a real-time PCR assay for detection of Plasmodium falciparum,
Plasmodium vivax, and Plasmodium ovale for routine clinical diagnosis. J Clin Microbiol. 2004;42:1214-9.

87. Lo E, Nguyen K, Nguyen J, Hemming-Schroeder E, Xu J, Etemesi H, et al. Plasmodium malariae prevalence and csp gene diversity, Kenya, 2014 and 2015. Emerg Infect Dis. 2017;23:601-10.

88. Baltzell KA, Shakely D, Hsiang M, Kemere J, Ali AS, Bjorkman A, et al. Prevalence of PCR detectable malaria infection among febrile patients with a negative Plasmodium falciparum specific rapid diagnostic test in Zanzibar. Am J Trop Med Hyg. 2013;88:289-91.

89. Veron V, Simon S, Carme B. Multiplex real-time PCR detection of $P$. falciparum, P. vivax and P. malariae in human blood samples. Exp Parasitol. 2009;121:346-51.

\section{Publisher's Note}

Springer Nature remains neutral with regard to jurisdictional claims in published maps and institutional affiliations.
Ready to submit your research? Choose BMC and benefit from:

- fast, convenient online submission

- thorough peer review by experienced researchers in your field

- rapid publication on acceptance

- support for research data, including large and complex data types

- gold Open Access which fosters wider collaboration and increased citations

- maximum visibility for your research: over $100 \mathrm{M}$ website views per year

At BMC, research is always in progress.

Learn more biomedcentral.com/submissions 